\title{
Is planned vaginal delivery for breech presentation at term still an option? Results of an observational prospective survey in France and Belgium
}

\author{
François Goffinet, MD, PhD, ${ }^{\mathrm{a}, \mathrm{b}}$ Marion Carayol, Midwife, ${ }^{\mathrm{a}}$ Jean-Michel Foidart, MD, $\mathrm{PhD},{ }^{\mathrm{c}}$ Sophie Alexander, \\ MD, PhD, ${ }^{\mathrm{d}}$ Serge Uzan, MD, ${ }^{\mathrm{e}}$ Damien Subtil, MD, PhD,${ }^{\mathrm{f}}$ Gérard Bréart, MD, ${ }^{\mathrm{a}, \mathrm{e}}$ for the PREMODA Study Group \\ INSERM U149, Epidemiological Research Unit on Perinatal Health and Women's Health, Université Pierre et Marie Curie Paris VI, \\ Hôpital Tenon ${ }^{a}$; Université Paris-Descartes Paris 5, Faculté de médecine, Service de gynécologie et obstétrique de Port-Royal, Hôpital \\ Cochin Saint-Vincent-de-Paul, Assistance Publique-Hôpitaux de Paris, France; Department of Obstetrics and Gynaecology, La Citadelle \\ Hospital, ${ }^{c}$ Liège, Belgium; School of Public Health School, Bruxelles, Belgium; Department of Obstetrics and Gynaecology, Tenon Hospital, \\ Assistance Publique-Hôpitaux de Paris, Université Pierre et Marie Curie Paris VI, ${ }^{e}$ France; Department of Obstetrics and Gynaecology, \\ Jeanne de Flandre Hospital, Lille Cedex, France
}

\begin{abstract}
Objective: A large trial published in 2000 concluded that planned vaginal delivery of term breech births is associated with high neonatal risks. Because the obstetric practices in that study differed from those in countries where planned vaginal delivery is still common, we conducted an observational prospective study to describe neonatal outcome according to the planned mode of delivery for term breech births in 2 such countries.

Study design: Observational prospective study with an intent-to-treat analysis to compare the groups for which cesarean and vaginal deliveries were planned. Associations between the outcome and planned mode of delivery were controlled for confounding by multivariate analysis. The main outcome measure was a variable that combined fetal and neonatal mortality and severe neonatal morbidity. The study population consisted of 8105 pregnant women delivering singleton fetuses in breech presentation at term in 138 French and 36 Belgian maternity units.

Results: Cesarean delivery was planned for 5579 women $(68.8 \%)$ and vaginal delivery for $2526(31.2 \%)$. Of the women with planned vaginal deliveries, 1796 delivered vaginally $(71.0 \%)$. The rate of the combined neonatal outcome measure was low in the overall population $(1.59 \% ; 95 \%$ CI [1.33-1.89]) and in the planned vaginal delivery group $(1.60 \% ; 95 \%$ CI [1.14-2.17]). It did not differ significantly between the planned vaginal and cesarean delivery groups (unadjusted odds ratio $=1.10,95 \% \mathrm{CI}[0.75-1.61]$ ), even after controlling for confounding variables (adjusted odds ratio $=1.40,95 \%$ CI $[0.89-2.23]$ ).

Conclusion: In places where planned vaginal delivery is a common practice and when strict criteria are met before and during labor, planned vaginal delivery of singleton fetuses in breech presentation at term remains a safe option that can be offered to women.
\end{abstract}

Keywords: Breech presentation Mode of delivery Neonatal morbidity Observational survey

Vaginal deliveries for breech presentations have long been a topic of debate. ${ }^{1}$ The Term Breech Trial by Hannah et al, published in 2000, confirmed for many physicians that neonatal risks associated with term breech births are much higher among planned vaginal deliveries and implied that cesarean deliveries should be systematically planned for all such women. ${ }^{2,3}$

Vaginal delivery of breech infants remains standard practice in France. In 1998, the proportion of planned vaginal deliveries among term breech infants here was $51.2 \%$, and $65.1 \%$ of this group actually delivered vaginally. ${ }^{4}$ In 2000, the French College of Gynecologists and Obstetricians (CNGOF) defined the optimal criteria for deciding to attempt vaginal delivery (Table I) ${ }^{5,6}$ Although the internal validity of Hannah's trial is irrefutable, some aspects raise questions about the extrapolation of its results to other settings. The absolute risk of mortality and serious perinatal morbidity for the planned vaginal birth group in countries with low perinatal mortality rates was high (5.7\%), as was the difference between the 2 groups (14 times higher in the vaginal than in the systematic cesarean delivery group). These risks were higher than reported in recent European series. ${ }^{7-11}$ Moreover, its obstetric practices appear to differ from those in countries where planned vaginal delivery is still offered to a large proportion of women with term breech presentations and satisfied only in part French guidelines for planned vaginal delivery. For example, pelvimetry was performed for only a minority of women. Management of labor for planned vaginal births also differed from French practices, with major disparities in methods of fetal surveillance, criteria for optimal dilatation rate, and duration of active pushing. ${ }^{12}$ 
Because our objective was to describe neonatal morbidity and mortality for term breech births for the entire population and according to the planned mode of delivery in countries where vaginal delivery is standard practice, we decided to conduct an observational survey without modifying obstetric practices.

\section{METHODS}

\section{Patients and study design}

Prospective data collection in maternity units volunteering for the PREMODA (PREsentation et MODe d'Accouchement: presentation and mode of delivery) study took place from June 1, 2001, through May 31, 2002 , in 138 centers in France, for 232,999 births, and from January 1, 2002, through December 31, 2002, in 36 centers in Belgium, for 31,106 births. The study was approved by the National Commission for Data Protection in Paris on May 9, 2001. It included all women giving birth in a participating maternity unit to a singleton fetus in breech presentation at term ( $\geq 37$ weeks' gestation), alive or not. The study did not modify patient management. A local investigator in each center was responsible for prospective data collection and monitoring data quality. This person forwarded data regularly to the regional and then national coordination offices, which also monitored them prospectively. Finally, at the end of the study, the national coordinator (M.C.) visited 20 randomly selected centers to evaluate data collection. Detailed reports were obtained (and supplemental information requested if necessary) for all deaths before discharge and transfers to neonatal intensive or intermediate care units. All existing autopsy reports were sought and obtained. All congenital anomalies and reasons for hospitalization were coded according to the 10th edition of the International Classification of Diseases. ${ }^{13}$ All deaths before discharge - fetal, neonatal, and postneonatal deaths — were reviewed by an independent expert committee (members listed in Appendix) to determine the cause of each death and whether a planned cesarean delivery at 39 weeks (as recommended by the CNGOF) might have prevented it.

\section{Outcomes and factors studied}

The principal outcome measure was a composite variable, similar to that used in the Term Breech Trial ${ }^{2}$ and including fetal and neonatal mortality and serious morbidity. It was defined as fetal or neonatal mortality at less than 28 days of age before discharge (excluding lethal congenital anomalies) or 1 or more of the following: birth trauma, including subdural hematoma, intracerebral or intraventricular hemorrhage, spinal-cord injury, basal skull fracture, peripheral-nerve injury present at discharge, or clinically significant genital injury; seizures occurring at less than 24 hours of age; 5-minute Apgar score of less than 4, intubation and ventilation for at least 24 hours, tube feeding for at least 4 days, or admission to the neonatal intensive care unit for longer than 4 days.

We examined the case files and recorded the items recommended by the CNGOF as a basis for deciding mode of delivery and the elements used for managing and monitoring labor (Table I). All participating centers systematically used continuous electronic fetal heart rate monitoring for fetal surveillance.

Table I-Items recommended by the CNGOF as a basis for deciding mode of delivery (2000 CNGOF guidelines [www.cngof. asso.fr]) and the elements used for describing management and monitoring labor

\section{Items recommended by the CNGOF as a basis for deciding mode of delivery}

Normal pelvimetry

No hyperextension of fetal head (checked with ultrasonography)

Fetal weight estimated between 2500 and $3800 \mathrm{~g}$

(with clinical and ultrasound examinations)

Frank breech

Continuous electronic fetal heart-rate monitoring for fetal surveillance during labor

Patient's informed consent

Elements used for describing management and monitoring labor

Induction or augmentation of labor with intravenous oxytocin

Lack of progress

Duration of the first stage of labor

Duration of passive and active phases of the second stage

Station at beginning of active pushing

Methods of vaginal breech delivery (spontaneous, assisted systematically, assisted for difficulty in delivery, manual or instrumental extraction) 


\section{Sample size}

We calculated that at least 4640 women had to be enrolled for us to be able to show a significant doubling of neonatal risk in the planned vaginal delivery group compared with the planned cesarean group (2\% vs $1 \%$; type II error $=0.20$, 2-sided type I error of 0.05 ), with a planned cesarean rate of $50 \%$ for the entire population.

\section{Definition of the study groups}

Our objective was to compare neonatal status according to the antenatal decision about mode of delivery. The planned cesarean delivery group was made up of the cesarean deliveries before labor, those planned before but performed after labor began and the vaginal deliveries when a cesarean delivery had been planned. All other women were considered to belong to the planned vaginal delivery group.

Table II- Maternal and obstetric characteristics in the planned vaginal and planned cesarean delivery groups

\begin{tabular}{|c|c|c|c|}
\hline & $\begin{array}{l}\text { Planned vaginal delivery } \mathrm{N} \\
=2,526 \\
\mathrm{n}(\%)\end{array}$ & $\begin{array}{l}\text { Planned caesarean section } \mathrm{N} \\
=5,579 \\
\mathrm{n}(\%)\end{array}$ & $P$ \\
\hline \multicolumn{4}{|l|}{ Maternal age } \\
\hline$\leq 21 \mathrm{y}$ & $164(6.6)$ & $287(5.2)$ & \multirow[t]{3}{*}{.02} \\
\hline $22-34 y$ & $1941(77.9)$ & $4301(77.8)$ & \\
\hline$\geq 35 y$ & $387(15.5)$ & $939(17.0)$ & \\
\hline \multicolumn{4}{|l|}{ Geographic origin } \\
\hline French & $1802(72.0)$ & $3756(67.9)$ & \multirow[t]{7}{*}{$<.001$} \\
\hline Belgian & $147(5.9)$ & $638(11.5)$ & \\
\hline European & $112(4.5)$ & $253(4.6)$ & \\
\hline North African & $185(7.4)$ & $339(6.1)$ & \\
\hline Subsaharan African & $64(2.6)$ & $127(2.3)$ & \\
\hline Other & $88(3.5)$ & $172(3.1)$ & \\
\hline Unspecified & $102(4.1)$ & $249(4.5)$ & \\
\hline \multicolumn{4}{|l|}{ Educational level } \\
\hline Primary school or less & $98(3.9)$ & $179(3.2)$ & \multirow{5}{*}{.005} \\
\hline Middle school & $461(18.3)$ & $898(16.1)$ & \\
\hline Secondary school & $357(14.1)$ & $916(16.4)$ & \\
\hline Postsecondary & $851(33.7)$ & $1825(32.7)$ & \\
\hline Not specified & $759(30.1)$ & $1761(31.6)$ & \\
\hline \multicolumn{4}{|l|}{ Parity } \\
\hline Nullipara & $1187(47.2)$ & $3249(58.7)$ & \multirow[t]{3}{*}{$<.001$} \\
\hline Primipara & $754(30.0)$ & $1487(26.8)$ & \\
\hline$>1$ para & $573(22.8)$ & $805(14.5)$ & \\
\hline \multicolumn{4}{|l|}{ Uterine scar } \\
\hline No & $2451(98.1)$ & $4620(83.4)$ & \multirow[t]{3}{*}{$<.001$} \\
\hline Single Scar & $45(1.8)$ & $742(13.4)$ & \\
\hline Two or more scars & $3(0.1)$ & $175(3.2)$ & \\
\hline \multicolumn{4}{|l|}{ Type of breech: } \\
\hline Complete breech & $750(29.7)$ & $1530(27.4)$ & \multirow[t]{3}{*}{$<.001$} \\
\hline Frank breech & $1669(66.1)$ & $3052(54.7)$ & \\
\hline Unspecified & $107(4.2)$ & $997(17.9)$ & \\
\hline \multicolumn{4}{|c|}{ Size of the maternity ward (births per y) } \\
\hline$<1000$ & $239(9.5)$ & $682(12.2)$ & \multirow[t]{3}{*}{$<.001$} \\
\hline$\geq 1000$ and $<2000$ & $1093(43.3)$ & $2450(43.9)$ & \\
\hline$\geq 2000$ & $1194(47.2)$ & $2447(43.9)$ & \\
\hline \multicolumn{4}{|l|}{ Type of the maternity ward } \\
\hline Public & $2035(80.6)$ & $1227(22.0)$ & \multirow[t]{2}{*}{.009} \\
\hline Private & $491(19.4)$ & $4352(78.0)$ & \\
\hline
\end{tabular}




\section{Analysis}

We first described the mode of delivery, cesarean indications and all fetal and neonatal deaths according to cause of death and mode of delivery. Obstetric practices related to the criteria for mode of delivery and the methods for monitoring labor were examined for the entire population, and the 2 groups compared for the neonatal morbidity criteria. Finally, all the factors associated with the principal outcome measure with a $P$ value less than .10 were included in a logistic regression model to obtain an adjusted odds ratio for planned vaginal delivery.

The groups were compared with a $\chi^{2}$ test (or exact Fisher test if required) for the analysis of categorical variables, and a 2 -sided $P$ value of less than .05 was defined as a significant difference. Statistical comparisons and logistic regressions were performed with Stata software version 8 (Stata Corp, College Station, TX).

Table III- Mode of delivery, birth weight, gestational age, and performance of a pelvimetry in the planned vaginal and planned cesarean delivery groups

\begin{tabular}{|c|c|c|c|}
\hline & $\begin{array}{l}\text { Planned vaginal delivery } \mathrm{N} \\
=2526 \\
\mathrm{n}(\%)\end{array}$ & $\begin{array}{l}\text { Planned cesarean section } \mathrm{N} \\
=5579 \\
\mathrm{n}(\%)\end{array}$ & $P$ \\
\hline \multicolumn{4}{|l|}{ Mode of delivery } \\
\hline Cesarean before labor & 0 & $4791(85.8)$ & \multirow[t]{12}{*}{$<.001$} \\
\hline Cesarean during labor & $732(29.0)$ & $757(13.6)$ & \\
\hline Vaginal delivery & $1794(71.0)$ & $31(0.6)$ & \\
\hline \multicolumn{3}{|l|}{ Reasons for cesarean before labor } & \\
\hline Breech & 0 & $2083(43.5)$ & \\
\hline Fetopelvic disproportion & 0 & $906(18.9)$ & \\
\hline Uterine scar & 0 & $535(11.2)$ & \\
\hline Patient's request & 0 & $468(9.8)$ & \\
\hline Fetal condition & 0 & $182(3.8)$ & \\
\hline Maternal associated disease & 0 & $174(3.6)$ & \\
\hline Other reasons & 0 & $359(7.5)$ & \\
\hline Unspecified & 0 & $84(1.7)$ & \\
\hline \multicolumn{4}{|l|}{ Reasons for cesarean during labor } \\
\hline Planned cesarean section & 0 & 757 & \\
\hline Failure to progress & $185(25.3)$ & 0 & \\
\hline FHR anomalies & $101(13.8)$ & 0 & \\
\hline Failure to progress and FHR anomalies & $77(10.5)$ & 0 & \\
\hline Diverse other reasons & $332(45.3)$ & 0 & \\
\hline Unspecified & $37(5.1)$ & 0 & \\
\hline \multicolumn{4}{|l|}{ Gestational age } \\
\hline 37 wks & $289(11.5)$ & $668(12.0)$ & \multirow[t]{5}{*}{$<.001$} \\
\hline 38 wks & $497(19.7)$ & $2094(37.6)$ & \\
\hline 39 wks & $715(28.3)$ & $1984(35.6)$ & \\
\hline $40 \mathrm{wks}$ & $688(27.3)$ & $559(10.0)$ & \\
\hline$\geq 41 \mathrm{wks}$ & $336(13.3)$ & $267(4.8)$ & \\
\hline \multicolumn{4}{|l|}{ Birth weight } \\
\hline$<2500 \mathrm{~g}$ & $154(6.1)$ & $293(5.3)$ & \multirow[t]{5}{*}{$<.001$} \\
\hline$\geq 2500$ and $<3000 \mathrm{~g}$ & $758(30.1)$ & $1604(28.8)$ & \\
\hline$\geq 3000$ and $<3500 \mathrm{~g}$ & $1104(43.7)$ & $2351(42.1)$ & \\
\hline$\geq 3500$ and $<4000 \mathrm{~g}$ & $443(17.6)$ & $1090(19.6)$ & \\
\hline$\geq 4000 \mathrm{~g}$ & $63(2.5)$ & $235(4.2)$ & \\
\hline \multicolumn{4}{|l|}{ Birth weight for gestational age* } \\
\hline$<10$ th & $142(5.7)$ & $228(4.1)$ & \multirow[t]{3}{*}{$<.001$} \\
\hline$\geq 10$ th and $\leq 90$ th & $2142(86.2)$ & $4610(83.3)$ & \\
\hline$>$ goth & $202(8.1)$ & $700(12.6)$ & \\
\hline Pelvimetry performed & $2064(82.5)$ & $3044(55.5)$ & $<.001$ \\
\hline
\end{tabular}

* Birth weight for gestational age was defined by birth weight $<10$ th, 10th-90th, and $>90$ th percentile of the birth weight distribution curve of Lubchenco et al. ${ }^{25}$ 


\section{RESULTS}

During the 12-month study period, 1,133 women were included in Belgium and 6,972 in France, for a total of 8,105 women delivering singleton fetuses in breech presentation at term. During the inclusion period, 264,105 births took place in the 174 centers, for a rate of singleton term fetuses in breech presentation of $3.1 \%$ $(8,105 / 264,105)$. Tables II and III report the general maternal and obstetric characteristics for the planned vaginal and cesarean delivery groups. The rate of planned cesarean delivery for the entire sample was $68.8 \%(\mathrm{n}=5,579)$ and differed widely between centers (median [10th-90th percentile] $=69.8 \%$ [47.8\%-89.0\%]). Breech presentation was the only reason for $43.5 \%$ of the cesarean deliveries before labor $(n=2,083)$. The rate of cesarean delivery during labor for the entire sample was $18.4 \%(\mathrm{n}=1,489)$, nearly half because women for whom cesarean delivery was planned went into labor before the date planned $(\mathrm{n}=757,50.7 \%)$. In all, 1,825 women $(22.5 \%)$ gave birth vaginally.

Table IV-Fetal and neonatal mortality and morbidity (excluding lethal congenital anomalies) in the planned vaginal delivery and planned caesarean section groups

\begin{tabular}{|c|c|c|c|}
\hline \multirow[b]{2}{*}{ 5-min Apgar } & \multirow[t]{2}{*}{$\begin{array}{l}\text { Planned vaginal delivery } \\
\mathrm{N}=2502 \\
\mathrm{n}(\% 95 \% \mathrm{CI})\end{array}$} & \multicolumn{2}{|c|}{$\begin{array}{l}\text { Planned caesarean section OR }[95 \% \mathrm{CI}] \\
\mathrm{N}=5573 \\
\mathrm{n}(\% 95 \% \mathrm{CI})\end{array}$} \\
\hline & & & \\
\hline$<4 *$ & $4(0.16[0.04-0.41])$ & $1(0.02[0.00-0.10])$ & $8.92[1.00-79.8]$ \\
\hline$<7$ & $37(1.48$ [1.04-2.03]) & $26(0.46[0.30-0.68])$ & $3.20[1.93-5.30]$ \\
\hline Total injuries & $45(1.80[1.31-2.40])$ & $26(0.46[0.30-0.68])$ & $3.90[2.40-6.34]$ \\
\hline Fracture clavicle & 15 & 5 & \\
\hline Fracture of humerus & 2 & 0 & \\
\hline Other fractures & 0 & 4 & \\
\hline Brachial plexus injuries* & 5 & 4 & \\
\hline Parietal skull fracture* & 1 & 0 & \\
\hline Sternocleidomastoid injury & 3 & 0 & \\
\hline Cutaneous wound with suture & 1 & 4 & \\
\hline Hematoma, contusions & 13 & 5 & \\
\hline Other injuries & 5 & 4 & \\
\hline Transfer to NICU & $54(2.16[1.63-2.81])$ & $91(1.63[1.32-2.00])$ & $1.33[0.94-1.86]$ \\
\hline NICU >4 days $*$ & $23(0.92[0.58-1.38])$ & $53(0.95[0.71-1.24])$ & $0.97[0.59-1.58]$ \\
\hline Intubation & $26(1.04[0.68-1.52])$ & $32(0.57[0.39-0.81])$ & $1.82[1.08-3.06]$ \\
\hline Persistent after the first $24 \mathrm{~h}^{*}$ & $10(0.40[0.19-0.73])$ & $21(0.38[0.23-0.58])$ & $1.06[0.50-2.26]$ \\
\hline Transfer to NICU & $140(5.60[4.73-6.57])$ & $280(5.04[4.47-5.68])$ & $1.12[0.91-1.38]$ \\
\hline Convulsions & $4(0.16[0.04-0.41])$ & $7(0.13[0.05-0.26])$ & $1.27[0.37-4.33]$ \\
\hline Continued after first $24 \mathrm{~h}^{*}$ & $1(0.04[0.00-0.22])$ & $4(0.07[0.02-0.18])$ & $0.56[0.06-4.98]$ \\
\hline Parenteral or tubal feeding $>4$ days $*$ & $15(0.60$ [0.34-0.98]) & $32(0.57[0.39-0.81])$ & $1.04[0.56-1.93]$ \\
\hline IVH & $1(0.04[0.00-0.22])$ & $2(0.04[0.004-0.13])$ & $1.11[0.10-12.28]$ \\
\hline Grade 1 & 0 & 1 & \\
\hline Grade 2 & 1 & 1 & \\
\hline Fetal death* & $2(0,08[0.009-0.28])$ & $7(0,13[0.05-0.26])$ & $0.64[0.13-3.06]$ \\
\hline Neonatal death* & 0 & $1(0.02[0.00-0.10])$ & - \\
\hline $\begin{array}{l}\text { Fetal and neonatal mortality or serious } \\
\text { neonatal morbidity }\end{array}$ & $40(1.60[1.14-2.17])$ & $81(1.45[1.16-1.81])$ & $1.10[0.75-1.61]$ \\
\hline \multicolumn{4}{|c|}{$\begin{array}{l}\text { Frequencies of morbidity criteria are calculated for live births. Intention-to-treat analysis of morbidity according to the planned mode of } \\
\text { delivery includes } 8075 \text { subjects rather than } 8105 \text { (difference }=30 \text { ) because this analysis excludes the } 17 \text { neonatal deaths with lethal } \\
\text { malformations ( } 6 \text { planned vaginal delivery and } 11 \text { planned cesarean sections), the } 4 \text { in utero deaths with lethal malformations (all vaginal } \\
\text { delivery), the pregnancy termination because of severe congenital CMV infection (vaginal delivery) and the } 8 \text { in utero deaths without a } \\
\text { decision about mode of delivery (all vaginal delivery) }(17+4+1+8=30 \text { ). NICU, Neonatal intensive care unit; IVH, intracerebral } \\
\text { ventricular hemorrhage; } C M V \text {, cytomegalovirus. } \\
\text { * Criteria included in the combined outcome "Fetal and neonatal mortality or serious neonatal morbidity." }\end{array}$} \\
\hline
\end{tabular}


The combined stillbirth and neonatal mortality rate was 3.9 per thousand births (22 fetal deaths and 10 neonatal deaths). In all, 6 of the 22 fetal deaths, and 17 of the 18 neonatal or postneonatal deaths before discharge were associated with a lethal congenital anomaly. Two of these deaths occurred in the delivery room, one associated with severe pontocerebellar atrophy and the other with severe ichthyosis. The only neonatal death not associated with a lethal congenital anomaly was sudden and unexplained, at home on day 15, and no cause was found.

Seven fetal deaths occurred at or after 39 weeks. The independent expert committee considered that 3 could have been avoided if the woman had received adequate antenatal care and agreed to a planned cesarean delivery at 39 weeks. In the first case, a woman who had already 2 previous caesarean deliveries refused 1 here, despite the recommendation of the obstetric team: when she came to the maternity ward at a term of 39 weeks +3 days for uterine contractions, in utero fetal death was diagnosed and remained unexplained. The second case involved a woman, gravida 2 , para 1 , with a previous cesarean delivery and normal prenatal care. Trial of vaginal delivery was planned but uterine rupture at 40 weeks resulted in an emergency caesarean delivery; the infant was stillborn. In the third case, the mother (gravida 7, para 5, and 42 years of age) sought prenatal care only during the second half of pregnancy, term was uncertain, and the file included no decision about mode of delivery. When she arrived at the maternity ward in labor at a term of 39 weeks +6 days, fetal death was diagnosed and remained unexplained.

Fetal or neonatal death or serious neonatal morbidity without lethal congenital anomalies was reported for 129 infants, or $1.59 \%$ of the entire sample (95\% CI [1.33-1.89]) and for 40 infants in the planned vaginal delivery group (1.60\% 95\% CI [1.14-2.17]). Table IV shows the perinatal outcome according to planned mode of delivery, after excluding lethal congenital anomalies. The groups did not differ significantly for the combined outcome of fetal or neonatal mortality or serious morbidity (odds ratio [OR] $=1.10,95 \% \mathrm{CI}[0.75-1.61]$. Of the criteria included in this combined variable, only a 5-minute Apgar score less than 4 was significantly more frequent in the planned vaginal group $(\mathrm{n}=4$ vs $\mathrm{n}=1, \mathrm{OR}=8.9,95 \% \mathrm{CI}$ [1.00-79.8]). Of the other individual outcomes, the following were significantly more frequent in the planned vaginal than in the planned cesarean group: 5-minute Apgar score less than $7(\mathrm{OR}=3.2,95 \% \mathrm{CI}$ [1.9-5.3]), total injuries (OR = 3.9, 95\% CI [2.4$6.3])$, and intubation $(\mathrm{OR}=1.8,95 \% \mathrm{CI}[1.08-3.1])$.

Factors significantly associated with fetal or neonatal mortality or severe morbidity with a threshold less than 0.10 were maternal age, educational level, parity, gestational age at delivery, birth weight, performance of pelvimetry, status of the maternity ward, and cesarean delivery before labor for fetal condition. After controlling for risk factors, the risk of fetal or neonatal mortality or serious morbidity was not significantly different among the planned vaginal and cesarean groups (adjusted $\mathrm{OR}=1.4095 \% \mathrm{CI}[0.89-2.23]$ ).

Table V reports management during labor and delivery for the vaginal deliveries.

\section{Comment}

This prospective study showed a global risk of $1.59 \%$ (95\% CI [1,33-1,89]) for fetal or neonatal mortality or serious neonatal morbidity among the overall population of singleton term breech infants. Vaginal delivery for breech presentation at term remained a common practice in 2001 through 2002 in France and Belgium (22.5\%). Under the standard practice conditions, neonatal outcome was not significantly poorer among infants with planned vaginal than with planned cesarean deliveries.

The participating maternity units account for a substantial portion of the births in France $(29.3 \%)(232,999 /$ $796,000)$ and French-speaking Belgium (47.9\%) (31,106/ 65,000). Inclusion of all term breech infants in each unit during the study period ensures that results represent current practices in these units. We included an average of 60 women per center during the study year and systematically recorded all available information about antenatal decisions as well as neonatal mortality and morbidity. The methodology we used allows us to meet the primary objectives of PREMODA, to describe practices on a daily basis for the entire population, and to assess neonatal mortality and morbidity in breech presentations in countries where vaginal delivery is still widely practiced. 
Table $\boldsymbol{V}$ - Management of Labor and delivery for vaginal deliveries

\begin{tabular}{ll}
\hline & $\mathrm{N}=1,825, \mathrm{~N}(\%)$ \\
\hline Induction of labor & $163(8.9)$ \\
First method used for induction: & \\
$\quad$ Prostaglandins & $45(28.7)$ \\
Oxytocin & $111(70.7)$ \\
$\quad$ Mechanical means & $1(0.6)$ \\
Oxytocin augmentation without labor induction & $1107(74.1)$
\end{tabular}

Lack of progress in dilatation

None

At least 1 failure to progress $>1 \mathrm{~h}$

$1534(87.2)$

At least 1 failure to progress $>2 \mathrm{~h}$

At least 2 episodes of failure to progress $>1 \mathrm{~h} \quad 14(0.8)$

Duration of first stage of labor between 5 and $10 \mathrm{~cm}$ dilatation

$\begin{array}{ll}<4 \mathrm{~h} & 1208(66.2) \\ 4-6 \mathrm{~h} & 248(13.6) \\ \geq 7 \mathrm{~h} & 25(1.4) \\ \text { Unspecified } & 344(18.8)\end{array}$

Duration of passive phase of second stage of labor

$\begin{array}{ll}<30 \mathrm{~min} & 1,093(63.9) \\ 30-60 \mathrm{~min} & 308(18.0) \\ \geq 60 \mathrm{~min} & 310(18.1)\end{array}$

Duration of active phase of second stage of labor

$\begin{array}{ll}<30 \mathrm{~min} & 1671(94.0) \\ 30-60 \mathrm{~min} & 103(5.8) \\ \geq 60 \mathrm{~min} & 4(0.2) \\ \text { Station at beginning of active pushing } & \\ \text { High } & 63(3.6) \\ \text { Mid } & 507(28.5) \\ \text { Low } & 1,017(57.1) \\ \text { Unspecified } & 195(10.8) \\ \text { Maneuvers during delivery } & \\ \text { None } & 633(35.3) \\ \text { Systematic* } & 543(30.3) \\ \text { For extended arms } & 226(12.6) \\ \text { For entrapped fetal head } & 71(4.1) \\ \text { For extended arms and entrapped } & 109(6.1) \\ \quad \text { fetal head } & \\ \text { Other } & 151(8.4) \\ \text { Maneuvers and forceps for entrapped fetal head } & 57(3.2) \\ \text { Difficulties during expulsion } & 87(4.8) \\ \text { Senior obstetrician present at delivery } & 1657(92.3)\end{array}$

* Many teams have a set of maneuvers they use routinely for breech deliveries, even when no difficulties arise.

Most large studies of term breech deliveries are retrospective and based on registry data. They generally report considerably increased neonatal risks in the vaginal delivery group. ${ }^{1,14-16}$ The many patients included in such studies allow statistically significant comparisons but their results are difficult to interpret because of the questionable validity and sparseness of the antenatal and postnatal information. In the PRE-MODA study, data were collected to answer the question about the association between mode of delivery and serious neonatal morbidity or mortality. Thus, we meticulously examined causes of death and morbidity. We noted neonatal conditions, including genetic syndromes and metabolic diseases, which were diagnosed days, or even weeks after birth, and required specific research. Of the 129 cases of fetal or neonatal death or severe neonatal morbidity, 33 (25.6\%) had nonlethal major or minor malformations that sometimes explained the abnormal neonatal condition. Similarly, large retrospective studies cannot deal with the question of prelabor decisions about mode of delivery because information about this decision was not collected. Prospective data recording 
enables an "intention-to-treat" analysis according to planned mode of delivery.

Although the groups were compared by an intention-to-treat analysis, their comparability cannot be guaranteed, as in a randomized controlled trial, and the multivariate analysis cannot completely control for all the confounding factors. Nonetheless, any selection bias is limited here by adjustment for factors such as educational level, quality of antenatal care, existence of a preliminary decision about mode of delivery, indications for the planned cesarean, and especially for fetal disorders.

Several examinations are performed routinely ante-natally to help decide mode of delivery. Although evidencebased proof of their usefulness is not available, the high rate of their performance is indicative of special attention to the decision. For example, comparison of PREMODA and the Term Breech Trial shows that physicians in the former used pelvimetry in the planned vaginal delivery group much more often $(82.4 \% \mathrm{vs}$ $9.8 \%)^{2}$ Management of labor also differed between these studies. Fetal surveillance of all PREMODA cases, but only $33.4 \%$ of those in the Term Breech Trial, used continuous FHR. The percentage of women with an active phase of the second stage of labor longer than 60 minutes was only $0.2 \%$ versus $5.0 \%$ in the Term Breech Trial. ${ }^{17,18} \mathrm{~A}$ secondary analysis of the latter reported that an adverse perinatal outcome was associated with an active phase of the second stage 60 minutes or more..$^{17}$ Active pushing began after the presenting part reached the high pelvic straits in only $3.6 \%$ of cases (information not reported in the Term Breech Trial). French guidelines recommend waiting to initiate active pushing in breech presentation until the presenting part reaches the outlet. This practice often leads to a long passive phase of the second stage of labor: 60 minutes or more in $18.1 \%$ in the PREMODA study versus $3.1 \%$ in the Term Breech Trial. ${ }^{17}$ Finally, only $3.8 \%$ of cases in our vaginal delivery group involved labor that failed to progress for more than 2 hours.

The PREMODA results in the planned vaginal delivery group can be extrapolated only to centers where planned vaginal deliveries are still relatively common. In a retrospective, population-based cohort study of 100,667 breech deliveries in California, Gilbert et al reported a high neonatal death rate among nullipara women in vaginal breech deliveries (OR 9.2, 95\% CI [3.3,25.6]), but no information about antenatal care or labor. The paucity of vaginal deliveries $(2.5 \%)$, however, indicates that this subgroup is probably quite particular. ${ }^{14}$

Similarly, the PREMODA results can be extrapolated only to centers that apply strict criteria before and during labor. The low risk in the planned vaginal delivery group may be associated with more prudent obstetric practices since the publication of the Term Breech Trial. According, the rate of cesarean delivery before labor for singleton term breech infants in France has increased from 49.0\% in 1998 to $75.0 \%$ in 2003 (Enquête National Périnatale 2003, unpublished data), a rise also seen in the Netherlands, Australia, and New Zealand. ${ }^{4,19,20}$ Although we do not have historic data for neonatal outcome in France, it is possible that the situation is similar to that observed in the Netherlands, where perinatal mortality decreased from $0.35 \%$ to $0.18 \%$ between 1998 and $2002 .^{21}$

The fetal or neonatal mortality or serious neonatal morbidity in planned vaginal deliveries in our study was barely one quarter that reported in the Term Breech Trial in its subgroup covering countries with low national perinatal mortality rates $(1.6 \%$ vs $5.7 \%)$. Although some individual unfavorable outcomes in the planned vaginal delivery group were similar between the 2 studies (intubation for more than 24 hours, trauma), most occurred more frequently in the Term Breech Trial (Apgar $<4$, seizures, brachial plexus injuries, intraventricular hemorrhage, neonatal deaths, excluding lethal malformations). Neither study, however, had enough subjects to interpret these individual outcomes meaningfully, this is why a combined outcome was necessary.

We did not find the excess risk associated with planned vaginal delivery that the Term Breech Trial observed for the subgroup covering countries with low national perinatal mortality rates (relative risk $[R R]=14.3$, CI 95\% [3.4-50.0]). ${ }^{2}$ Moreover, their recent subgroup analysis found that the prevalence of death or abnormal neurodevelopment at 2 years did not differ according to study group (vaginal or cesarean). ${ }^{22}$ When we consider only deaths rather than morbidity, our study included only 1 neonatal death of a nonmalformed newborn infant and that 1 was in the planned cesarean group.

Except for a 5-minute Apgar score less than 4 ( $n=4$ vs $n=1$, respectively), none of the severe individual outcomes differed significantly between groups. The composite outcome was selected because it was very similar to that used in the Term Birth Trial and because the PREMODA scientific study considered it to be a thorough characterization of a poor condition in term neonates likely to result in long-term sequelae. Some other individual neonatal outcomes were significantly higher in the planned vaginal than in the cesarean delivery group. Among these individual outcomes, some cases, probably those at highest risk, were included in the composite variable because they met more serious criteria (ie, 16/63 of those with an Apgar score $<7 ; 40 / 58$ of 
intubated infants; $13 / 71$ of those with trauma). The multivariate analysis was based only on the principal outcome variable, precisely to avoid multiple comparisons that increase the risk of observing significant differences by chance, especially in small groups.

We are not the only group to have obtained results along this line: numerous recent studies that applied a relatively widespread policy of planned vaginal delivery, in various practice conditions, did not observe this excess risk. ${ }^{7-11}$ The methodology for studying policies for managing delivery of term breech infants necessarily differs somewhat from that for studying the biologic effect of drugs. Randomized trials assessing a management policy are necessary but difficult to extrapolate to other practice conditions. ${ }^{23,24}$ It is accordingly essential to assess a management policy in a population under conditions of everyday practice.

\section{CONCLUSION}

In centers where planned vaginal delivery remains a widespread practice and in complying with rigorous conditions before and during labor, we did not find a significant excess risk associated with planned vaginal delivery compared with planned cesarean for women with a singleton fetus in breech presentation at term. There may be a slightly higher neonatal risk associated with planned vaginal delivery but it is very different from that reported in the only published large randomized trial. Under the conditions discussed here, planned vaginal delivery of singleton fetuses in breech presentation at term remains a safe clinical option that can be offered to women after providing them with clear, objective, and complete information.

\section{References}

1. Cheng M, Hannah M. Breech delivery at term: a critical review of the literature. Obstet Gynecol 1993;82:605-18.

2. Hannah ME, Hannah WJ, Hewson SA, Hodnett ED, Saigal S, Willan AR. Planned caesarean section versus planned vaginal birth for breech presentation at term: a randomised multicentre trial. Term Breech Trial Collaborative Group. Lancet 2000;356: 1375-83.

3. Lumley J. Any room left for disagreement about assisting breech births at term? Lancet 2000;356:1369-70.

4. Blondel B, Norton J, du Mazaubrun C, Breart G. Development of the main indicators of perinatal health in metropolitan France between 1995 and 1998: results of the national perinatal survey [in French]. J Gynecol Obstet Biol Reprod (Paris) 2001; 30:552-64.

5. Carbonne B, Goffinet F, Breart G, Frydman R, Maria B, Uzan S. The debate on breech presentation: Delivery of breech presentations: the position of the National College of French gynecologists [in French]. J Gynecol Obstet Biol Reprod (Paris) 2001;30:191-2.

6. Collège National des Gynécologues et Obstétriciens Français. Présentation du siège. Voie basse ou césarienne systématique? Mise au point du 28.04.2001. Available at: http://www.cngof.asso.fr. Accessed on April 28, 2001.

7. Alarab M, Regan C, O'Connell MP, Keane DP, O'Herlihy C, Foley ME. Singleton vaginal breech delivery at term: still a safe option. Obstet Gynecol 2004;103:407-12.

8. Giuliani A, Scholl WM, Basver A, Tamussino KF. Mode of delivery and outcome of 699 term singleton breech deliveries at a single center. Am J Obstet Gynecol 2002;187:1694-8.

9. Golfier F, Vaudoyer F, Ecochard R, Champion F, Audra P, Rau-drant D. Planned vaginal delivery versus elective caesarean section in singleton term breech presentation: a study of 1116 cases. Eur J Obstet Gynecol Reprod Biol 2001;98:186-92.

10. Irion $\mathrm{O}$, Hirsbrunner Almagbaly $\mathrm{P}$, Morabia A. Planned vaginal delivery versus elective caesarean section: a study of 705 singleton term breech presentations. BJOG 1998;105:710-7.

11. Kayem G, Goffinet F, Clement D, Hessabi M, Cabrol D. Breech presentation at term: morbidity and mortality according to the type of delivery at Port Royal Maternity hospital from 1993 through 1999. Eur J Obstet Gynecol Reprod Biol 2002;102:137-42.

12. Goffinet F, Blondel B, Breart G. Breech presentation: questions raised by the controlled trial by Hannah et al. on systematic use of cesarean section for breach presentations. J Gynecol Obstet Biol Reprod (Paris) 2001;30:187-90.

13. World Health Organization. The International Statistical Classification of Diseases and Related Health Problems. 10th revision. Geneva: WHO; 1993.

14. Gilbert WM, Hicks SM, Boe NM, Danielsen B. Vaginal versus cesarean delivery for breech presentation in California: a populationbased study. Obstet Gynecol 2003;102:911-7.

15. Rietberg CC, Elferink-Stinkens PM, Brand R, van Loon AJ, Van Hemel OJ, Visser GH. Term breech presentation in The Netherlands from 1995 to 1999: mortality and morbidity in relation to the mode of delivery of 33824 infants. BJOG 2003;110:604-9. 
16. Roman J, Bakos O, Cnattingius S. Pregnancy outcomes by mode of delivery among term breech births: Swedish experience 1987-1993. Obstet Gynecol 1998;92:945-50.

17. Su M, Hannah WJ, Willan A, Ross S, Hannah ME. Planned caesarean section decreases the risk of adverse perinatal outcome due to both labour and delivery complications in the Term Breech Trial. BJOG 2004;111:1065-74.

18. Su M, McLeod L, Ross S, Willan A, Hannah WJ, Hutton E, et al. Factors associated with adverse perinatal outcome in the Term Breech Trial. Am J Obstet Gynecol 2003;189:740-5.

19. Molkenboer JF, Bouckaert PX, Roumen FJ. Recent trends in breech delivery in the Netherlands. BJOG 2003;110:948-51.

20. Phipps H, Roberts CL, Nassar N, Raynes-Greenow CH, Peat B, Hutton EK. The management of breech pregnancies in Australia and New Zealand. Aust N Z J Obstet Gynaecol 2003;43:294-7; discussion 261.

21. Rietberg CC, Elferink-Stinkens PM, Visser GH. The effect of the Term Breech Trial on medical intervention behaviour and neonatal outcome in The Netherlands: an analysis of 35,453 term breech infants. BJOG 2005;112:205-9.

22. Whyte H, Hannah ME, Saigal S, Hannah WJ, Hewson S, Amankwah K, et al. Outcomes of children at 2 years after planned cesarean birth versus planned vaginal birth for breech presentation at term: the International Randomized Term Breech Trial. Am J Obstet Gynecol 2004;191:864-71.

23. Bréart G, Blondel B, Goffinet F. Methods in evaluation: an appropriate response to each question. In: Blondel B, Goffinet F, Bréart G, editors. Evaluation in perinatology: a guide for evidence-based practice. Paris: Masson; 2001.

24. Kotaska A. Inappropriate use of randomised trials to evaluate complex phenomena: case study of vaginal breech delivery. BMJ 2004;329:1039-42.

25. Lubchenco LO, Hansman C, Dressier M, Boyd E. Intrauterine growth as estimated from liveborn birth-weight data at 24 to 42 weeks of gestation. Pediatrics 1963;32:793-800.

\section{APPENDIX}

\section{PREMODA Study Group}

Writing Committee: F. Goffinet, M. Carayol, J. M. Foidart, G. Bréart.

Scientific Committee: F. Goffinet, S. Alexander, J. M. Foidart, S. Uzan, D. Subtil, G. Bréart.

Data Monitoring and Analysis Committee: M. Carayol, F. Goffinet, D. Subtil, S. Alexander, J. M. Foidart, G. Bréart.

Independent Expert Committee: Pediatricians: Pr U Simeoni (TIMONE Hospital, Marseille, France); Pr JC Rozé (Mother and Children's Hospital, Nantes, France); Pr JB Gouyon (Dijon University Hospital, France); Pr P Lequien (Jeanne de Flandre Hospital, Lille, France); P.H. Jarreau (Port-Royal Maternity, Cochin Hospital, Paris, France); Pr D Haumont (Saint-Pierre University Hospital, Brussels, Belgium). Obstetricians: Pr F Puech (Jeanne de Flandre Hospital, Lille, France); Pr P Gaucherand (Croix-Rousse Hospital, Lyon, France)

List of collaborators and participating centers.

\section{France}

Région Alsace: Coordinator: Pr Langer: CHU de Strasbourg (Pr Langer), CMCO de Schiltigheim (Dr Vayssiere), CHR de Haguenau (Dr Lehmann), CMC de Colmar (Dr Kutnahorsky), CHR de Mulhouse (Dr Wiedemann), Clinique Sainte Anne, Strasbourg (Dr Jeanmougin), Clinique Diaconat, Mulhouse (Dr Blum)Basse-Normandie: Coordinator: Pr Dreyfus: CHU de Caen (Pr Dreyfus/Dr Denoual-Ziad), CH de Cherbourg (Dr Ulmann), CH de Lisieux (Dr Zerger), CH de Saint Lo (Dr Refahi), CH de Fiers (Dr André), CH de la Ferté Macé (Dr Nelle)—Région Bretagne: Coordinator: Pr Grall: CHU de Brest (Pr Collet), CHU Hôtel Dieu, Rennes (Pr Poulain), CHU Hôpital Sud, Rennes (Mme Pérrigot), CH de Lorient (Dr Getin), Clinique mutualiste de la Sagesse, Rennes (Dr Aussel), CH de Saint Brieuc (Dr Giono-Renaud), CH de Saint Malo (Dr Weyl), CH de Vannes (Mme Pierson), CH de Cornouaille (Dr Germain)—Région Centre: Coordinator: Pr Perrotin: CHU Bretonneau, Tours (Dr Alonso), CHU Beffroi, Tours (Dr Rapp), CH de Blois (Dr Montmasson), CHR d'Orléans (Dr Ceccaldi), CHG de Chartres (Dr Guilbaud)_-Région Franche-Comté: Coordinator: Pr Schaal: CHU de Besançon (Dr Riethmuller), CHG de Montbéliard (Dr Zurlinden), CHG de Belfort (Dr Terzibachian)—Région Haute-Normandie: Coordinator: Pr Verspyck: CHU de Rouen (Pr Verspyck), CH de Mont Saint Aignan (Dr 
Fournet), CH du Havre (Dr Degré), CH d'Elbeuf (Dr Paquet), CH de Dieppe (Dr Gandour), Clinique SaintRomain, Rouen (Dr Thobois)—Région Ile de France: Réseau Sud Ouest Francilien: Coordinator: Dr Audibert: CHU de Clamart (Dr Audibert), Clinique des Vallées, Châtenay-Malabry (Dr Proust), Clinique de Meudon la Forêt (Dr Chene), CH de Dourdan (Dr Lambert), CH Sud Francilien site d'Evry (Mme Lose), CH de Fontainebleau (Dr Fillippini), CH d'Orsay (Dr Devianne); Réseau Ile de France Port-Royal: Coordinator: Dr Harvey: CHU Cochin, Paris (Dr Kayem), CHU Saint Vincent de Paul, Paris (Pr Lepercq), CHU Saint Antoine, Paris (Pr Carbonne), CH Notre Dame de Bonsecours, Paris (Dr Grovangrandi), CHU Beaujon, Paris (Mme Grapin), CHU de Colombes (Dr Crenn-Hebert), CH de Neuilly sur Seine (Dr Galimard), CH de Saint Cloud (Mme Pecourt), Hôpital Militaire Begin, Saint Mandé (Dr Ponties), Clinique Armand Brillard, Nogent sur Marne (Dr Helvin), CH Les Diaconesses, Paris (Dr Harvey); Réseau de Poissy: Coordinator: Dr Rozenberg: CHI de Poissy-Saint Germain (Mme Bertaud); Réseau intermaternités de Saint-Denis: Coordinator: Pr Uzan: $\mathrm{CH}$ de Bondy (Dr Seince), CHI de Montreuil (Dr Chitrit), CHI de Villepinte (Dr Debièvre), Clinique Vauban, LivryGardan (Dr Kamoun), Clinique du bois d'amour, Drancy (Dr Masson), CH de Montfermeil (Dr Ropert), CHG de Saint-Denis (Dr Ekoukou), Clinique de l'Estrée, Stains (Dr Franche); Réseau Tenon: Coordinators: Pr Uzan and Dr Berkane: CHU Tenon, Paris (Dr Berkane), CHU Bichat, Paris (Pr Mandelbrot); CHI de Créteil (Pr Haddad et Dr Touboul); CH de Saint Maurice (Dr Bardou)—Région Limousin: Coordinator: Pr Philippe: CH de Brive (Mme Peron), CH de Tulle (Mme Barbé), CHU de Limoges (Dr Eyraud), CH d'Ussel (Mme Leclerc)—Région Lorraine: Coordinator: Pr Boutroy, Dr Thiebaugeorges: CHU de Nancy (Dr Thiebau-georges), CH d'Epinal (Dr Scotton), CHR Bonsecours, Metz (Dr Lemarié), CH de Thionville (Dr Szwarcberg), CH Sainte Croix, Metz (Dr Ragage), Polyclinique Ma-jorelle, Nancy (Dr Bey), Clinique Arc en Ciel, Epinal (Dr Gaillet-Schiochet), Clinique Claude Bernard, Metz (Dr Adami) — Nord Pas de Calais: Coordinator: Pr Subtil: CH d'Arras (Mme Finet), CH de Béthune (Dr Hay), CH de Boulogne (Dr Churlet), Clinique Côte d'Opale, Saint Martin les Boulognes (Dr Renault), CH de Douai (Dr Dognin), Clinique Saint Amé, Lambre-lez-Douai (Dr Doutrelant), Clinique Villette, Dunkerque (Mme Gosselin, Mme Deroose), CH de Maubeuge (Dr Hubert), CH de Roubaix (Dr Le Goueff), CH de Seclin (Dr Biausque), CH de Valenciennes (Dr Massoni), CHU de Lille (Pr Subtil), Clinique Cotteel, Villeneuve d'Ascq (Mme Dumon)—-Région Pays de Loire: Coordinator: Dr Winer: CHD La Roche sur Yon (Dr Barreteau), CH de Saint Nazaire (Dr Gerard), Clinique du jardin des plantes, Saint Nazaire (Dr Rousseau), CH de Cholet (Dr Aireau), CHU de Nantes (Dr Winer), Maison de naissance, St Sébastien/Loire (Dr Berlivet), CHU d'Angers (Dr Gilard)_-Picardie: Coordinator: Pr Gondry: CHU d'Amiens (Pr Gondry), Clinique Sainte Claire, Amiens (Dr Degroote), CHG de Beauvais (Dr Manela), CHG de Creil (Dr Cesbron), CHG de Laon (Dr Boury), CHG de Saint Quentin (Dr Closset), CHG de Soissons (Dr Abboud)—Région PoitouCharentes: Coordinator: Pr Pierre: CHU de Poitiers (Pr Pierre), Clinique du Fief de Grimoire, Poitiers (Dr Bascou), CHG de Niort (Dr Breheret), CHG d'Angoulême (Dr Tariel), CHG de la Rochelle (Dr Quentin), Clinique Sainte Anne, Châteller-ault (Dr Boisselier), CHG de Châtellerault (Dr Godard), CHG de Bressuire (Dr Villemonteix), CHG de Saintes (Dr Trousselle)—Région Provence Alpes Côtes d'Azur: Coordinator: $\operatorname{Pr}$ D'Ercole: CHU la Conception, Marseille (Dr Agostini), CHR de Draguignan (Dr Diquelou), CHR de Hyères (Dr Eymery), CHR de la Ciotat (Dr Pechikof), CHU Hôpital Nord, Marseille (Pr D'Ercole), CHR de Salon de Provence (Dr Maldiney), CHR de la Seyne sur Mer (Dr Joly)—Région Rhône-Alpes Lyon: Coordinator: Dr Vaudoyer: CHU l'Hôtel Dieu, Lyon (Dr Vau-doyer), CHU la Croix Rousse, Lyon (Pr Gaucherand), CHU Lyon Sud, Lyon (Dr Coste)—Région Rhône-Alpes Grenoble: Coordinator: Dr Vendittelli: CHU Nord et Sud, Grenoble (Dr Venditelli), Clinique Belledone, Saint Martin d'Hères (Dr Benbassa), Clinique des Cédres, Grenoble (Dr Boschetto), Clinique Mutualiste, Grenoble (Dr Leger), CHU de Saint Etienne (Dr Collet), CH de Bourg en Bresse (Dr Frobert), CH d'Alberville (Dr Dardenne), CH de Chambéry (Dr Houman), CH d'Annecy (Dr Bernardi), CH de Valence (Dr Broussard), CH de Roanne (Dr Gaja), CH d'Evian les Bains et de Thonon les Bains (Dr Thery), CH de Saint Julien en Genevois (Dr Tognelli), CH de Firminy (Dr Albersammer).

\section{Belgium}

Belgium Coordinator: Pr Foidart: CH Luxembourg (Dr Arendt), Hôpital St Nikolaus Eupen (Dr Chantraine), Hôpital Ste Anne-St-Remi Bruxelles (Dr Befahy), CH Etterbeek-Ixelles (Dr Houben), Hôpital Braine l'Alleud Waterloo Lillois (Dr Busine), Hôpital St Elisabeth Bruxelles (Dr Depierreux), CHR War-quignies Boussu (Dr Mathieu), IFAC Ste Thérèse Bastogne (Dr Colin), RHMS La Madeleine Ath (Dr Coulon), CHU Saint-Pierre Bruxelles (Dr Barlow), RHMS Tournai (Dr Delvoye), CH Françoise Rabelais Cesar de Paepe Bruxelles (Dr Verougstraete), CH Peltzer La Tourelle Verviers (Dr Deville), Centre de Santé des Fagnes Chimay (Dr Dewille), CHR Namur (Dr D'Huslt), Hôpital St Joseph Mons (Dr du Bois d'Enghien), CHU Liège (Pr Foidart), CHU Tivoli La Louvière (Dr Francotte), CHR Haute Senne Soignies (Dr Gielen), IFAC Princesse Paola Marche (Dr Gilles), CHR Val de Sambre Auvelais (Dr Verheyen), Cliniques Universitaires St Luc Bruxelles (Pr Bernard, Pr Hubinont), CH Mouscron (Dr Jacob), Hôpital Reine Astrid Malmedy (Dr Lavalleye), CHU Brugmann Bruxelles (Pr Vokaer), Hôpital St Pierre Ottignies (Dr Longueville), CH Jolimont (Dr Guilmot), CHU Erasme Bruxelles (Dr Kirkpatrick), CH Notre Dame Charleroi (Dr Sartenaer), CH Hornu-Frameries (Dr Semoulin), CHBA Seraing 
(Pr Van Cauwenberge), Hôpital St Jean Bruxelles (Dr Venderick), CH François Rabelais Français Reine Elisabeth Bruxelles (Dr Vermeulen), Hôpital Notre Dame des Bruyères Chenée (Dr Vigis), Hôpital Notre Dame Tournai (Dr Wauters), Hôpital Notre Dame Hermalle (Dr Romedenne).

\section{Contributors}

F. Goffinet, D. Subtil, S. Uzan, S. Alexander, and G. Bréart were responsible for the study design. F. Goffinet, M. Carayol, J. M. Foidart, and G. Bréart wrote the paper. M. Carayol and F. Goffmet coordinated and supervised the study for France, S. Alexander and J. M. Foidart for Belgium. M. Carayol, F. Goffmet, D. Subtil, and G. Bréart conducted the analyses.

All members of the Writing, Scientific, and the Data Monitoring and Analysis committee have seen and approved the final version of the manuscript.

The study was approved by the National Commission for Data Protection in Paris (on 9 May, 2001). 